GTP-18-1556

\title{
MULTIPHASE CFD MODELING OF EXTERNAL OIL FLOW FROM A JOURNAL BEARING
}

\author{
Martin Berthold \\ Gas Turbine and Transmissions \\ Research Centre (G2TRC), \\ University of Nottingham, \\ Nottingham, UK
}

\author{
Prof. Hervé Morvan, \\ Dr. Richard Jefferson-Loveday, \\ Dr. Benjamin C Rothwell, \\ Dr. Stephen Ambrose \\ Gas Turbine and Transmissions Research Centre \\ (G2TRC), University of Nottingham, Nottingham, UK
}

\author{
Dr. Colin Young \\ Rolls-Royce plc \\ Derby, UK
}

\section{ABSTRACT}

High loads and bearing life requirements make journal bearings a potential choice for use in high power, epicyclic gearboxes in jet engines. Particularly in a planetary configuration the kinematic conditions are complex. With the planet gears rotating about their own axis and orbiting around the sun gear, centrifugal forces generated by both motions interact with each other and affect the external flow behavior of the oil exiting the journal bearing.

Computational Fluid Dynamics (CFD) simulations using the Volume of Fluid (VoF) method are carried out in ANSYS Fluent [1] to numerically model the two-phase flow behavior of the oil exiting the bearing and merging into the air surrounding the bearing.

This paper presents an investigation of two numerical schemes that are available in ANSYS Fluent to track or capture the air-oil phase interface: the geometric reconstruction scheme and the compressive scheme. Both numerical schemes are used to model the oil outflow behavior in the most simplistic approximation of a journal bearing: a representation, rotating about its own axis, with a circumferentially constant, i.e. concentric, lubricating gap. Based on these simplifications, a three dimensional (3D) CFD sector model with rotationally periodic boundaries is considered.

A comparison of the geometric reconstruction scheme and the compressive scheme is presented with regards to the accuracy of the phase interface reconstruction and the time required to reach steady state flow field conditions. The CFD predictions are validated against existing literature data with respect to the flow regime, the direction of the predicted oil flow path and the oil film thickness. Based on the findings and considerations of industrial requirements, a recommendation is made for the most suitable scheme to be used.

With a robust and partially validated CFD model in place, the model fidelity can be enhanced to include journal bearing eccentricity. Due to the convergent-divergent gap and the resultant pressure field within the lubricating oil film, the outflow behavior can be expected to be very different compared to that of a concentric journal bearing. Naturally, the inlet boundary conditions for the oil emerging from the journal bearing into the external environment must be consistent with the outlet conditions from the bearing. The second part of this paper therefore focuses on providing a method to generate appropriate inlet boundary conditions for external oil flow from an eccentric journal bearing.

\section{INTRODUCTION}

A step change in jet engine efficiency can be achieved by decoupling the fan from its driving turbine. The key technology to enable this advance is an epicyclic reduction gearbox (Figure $1)$.

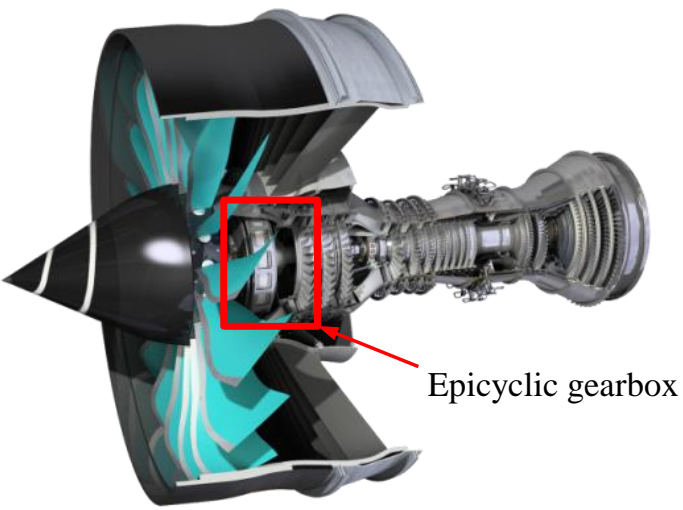

Figure 1: Rolls-Royce Ultrafan ${ }^{\circledR}$ engine with epicyclic gearbox [2]

Figure 2 shows a schematic diagram of an epicyclic gearbox in planetary configuration. 


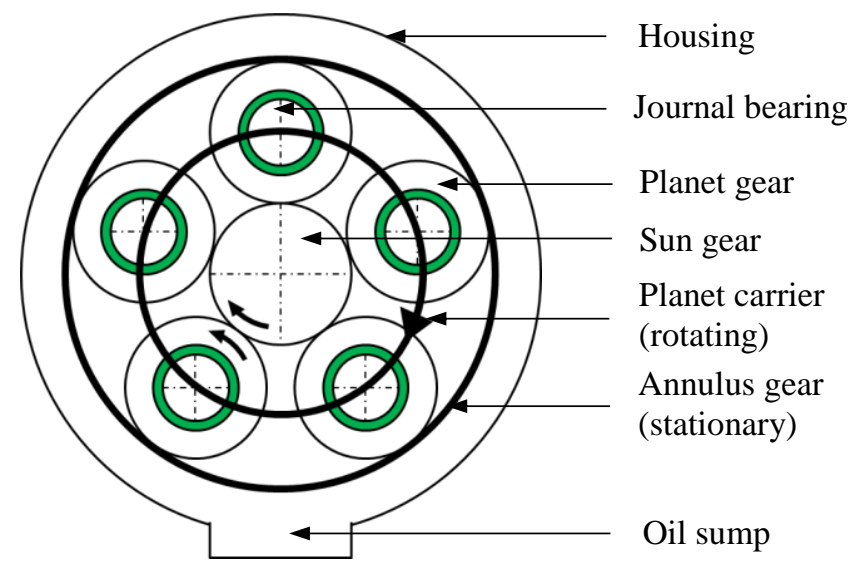

Figure 2: Epicyclic gearbox in planetary configuration

Figure 3 shows the tooth forces, $F_{\tan , 1}$ and $F_{\tan , 2}$, and the centrifugal force, $F_{\mathrm{c}}$, due to the carrier rotation, acting on the planet gear. The resultant gear force, $F_{\text {res }}$, lies in sector I. Consequently, the resultant bearing force and the location of the minimum lubricating film height lie in sector III. It should be noted that the exact locations of the resultant bearing force and the minimum film height depend on the operating conditions of the planetary gearbox.

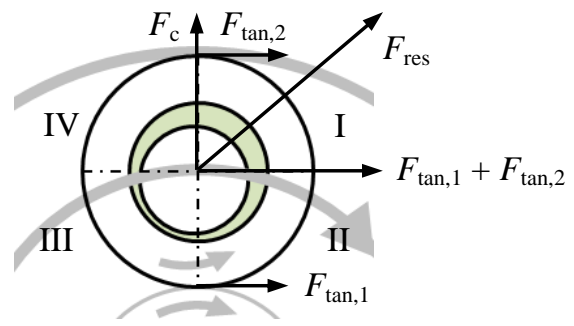

Figure 3: Forces acting on planet gear

Due to the very high loads transmitted by the gearbox, even a small power loss leads to significant generation of heat. In order to remove this heat, substantial quantities of coolant are required, a large amount of which is supplied to the planet bearings [3]. Effective and efficient flow path management is therefore essential. Failure to design an effective oil scavenge system can lead to a number of issues, all of which have been previously discussed in [4].

In order to ensure reliable gearbox operation and maximum oil scavenge effectiveness, a comprehensive understanding is required of the oil flow as it exits the journal bearing. An analysis approach, including initial results, is presented in [4].

In industrial environments it is particularly important for CFD simulations to deliver meaningful results quickly, especially when required to support decision making processes during the design phase or failure root cause investigations. Multiphase CFD modeling typically requires a transient analysis approach in order to compute a time-dependent solution. Thus, the computational effort needed for simulating the flow behavior is often in strong contrast to the time available. This currently prevents multiphase CFD from being used routinely for the purposes mentioned above and efforts to accelerate multiphase CFD simulations are urgently required.

\section{ANALYSIS APPROACH}

A strategy of decomposing a journal bearing in the complex environment of an epicyclic planetary gearbox (Figure 2) into simpler models was proposed in [4]. In its most basic form a journal bearing can be modeled by two concentric cylinders, creating an axially and circumferentially constant lubricating gap height, $h$, as shown in Figure 4.

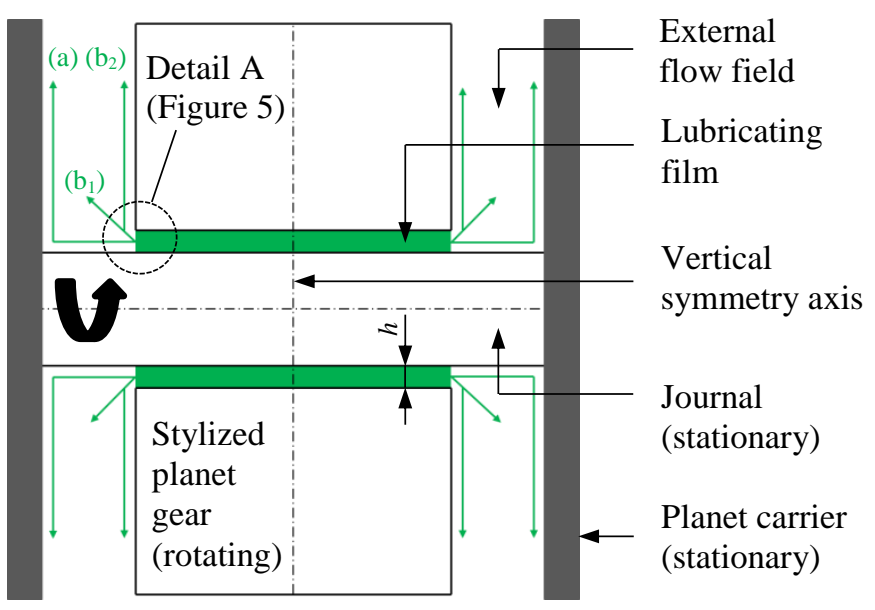

Figure 4: Simple journal bearing model with axially and circumferentially constant lubricating gap height, $h$, and possible exit flow directions $(a, b)$ according to [4]

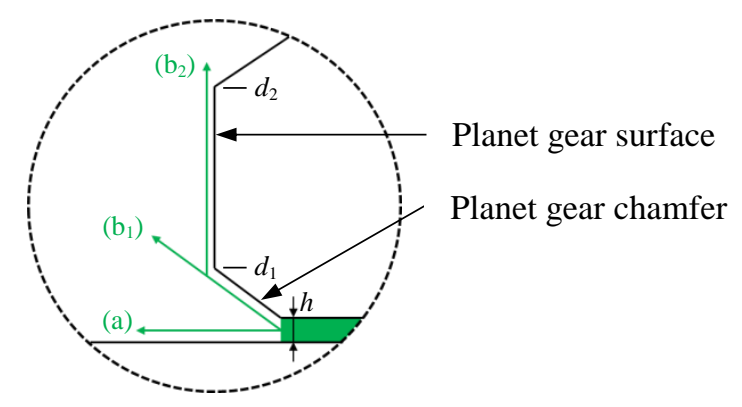

Figure 5: Detail A of planet gear (Figure 4) with possible exit flow directions $(a, b)$ according to [4]

\section{NUMERICAL METHODS SUITABLE FOR MODELING EXTERNAL OIL FLOW FROM A JOURNAL BEARING}

Numerical models suitable for modeling external oil flow from a journal bearing were previously reported in [4]. The modeling approaches can be categorized according to their kinematic description. There are two different mathematical representations of fluid flow; the Lagrangian and the Eulerian approaches.

Among the Lagrangian approaches, the Discrete Phase 
Model (DPM) and the Smoothed Particle Hydrodynamics (SPH) methods are currently of interest for solving this type of two-phase flow. The Eulerian approaches that are typically used include the Eulerian method, Volume of Fluid (VoF) and LevelSet (LS) methods.

Based on its capabilities, the VoF method is deemed the most appropriate for simulations of external oil flow from a journal bearing. The main advantage of this method lies in its ability to capture a wide range of flow regimes, i.e. droplets, ligaments, sheets and films, providing the computational grid is sufficiently fine. Moreover, in comparison with other methods with similar capabilities, i.e. the Eulerian method, the VoF method is computationally less expensive.

\section{PHASE INTERFACE RECONSTRUCTION}

In the case of the VoF method, the physical properties of the fluid in each calculational cell are determined by the volume fraction, $\alpha_{\mathrm{q}}$, of each phase. The volume fraction can vary between zero and one. Cells which are completely filled with oil will have an oil volume fraction of one. Cells that are completely filled with air will have an oil volume fraction of zero. Cells with an oil volume fraction between zero and one will contain the phase interface.

ANSYS Fluent [1] provides multiple numerical models to track or capture the phase interface between the air and the oil. Based on their accuracy and required computational effort, the geometric reconstruction scheme and the compressive scheme are commonly used.

The geometric reconstruction scheme tracks the phase interface based on geometrical information. A piecewise linear interface construction (PLIC) is used to represent the phase interface [5, 6] (Figure 6).

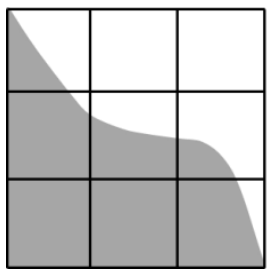

\begin{tabular}{|c|c|c|}
\hline 0.4 & 0 & 0 \\
\hline 0.9 & 0.5 & 0.3 \\
\hline 1 & 1 & 0.8 \\
\hline
\end{tabular}

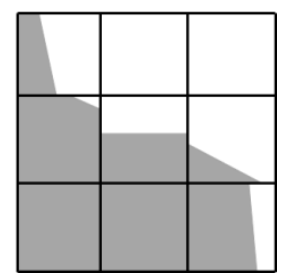

Figure 6: Schematic diagram of phase interface reconstruction using the geometric reconstruction scheme with true interface (left), oil volume fractions (middle) and piecewise linear reconstructed interface (right)

In ANSYS Fluent, this scheme is considered to be the most accurate of the options available [7]. However, it requires an explicit volume fraction discretization scheme. Hence, the size of the time-step for the transient computation is limited by the Courant number, $C$, which is defined as

$$
C=u \Delta t / \Delta z
$$

In the above equation, $u$ is the liquid velocity, $\Delta t$ is the time-step and $\Delta z$ is the grid spacing. When using an explicit discretization scheme, $C$ should be less than or equal to one to avoid numerical stability issues and maintain an accurate solution.

The compressive scheme is an interface capturing scheme based on algebraic information. It is a second order scheme based on the slope limiter [6].

$$
\Phi_{\mathrm{f}}=\Phi_{\mathrm{d}}+\beta \nabla \Phi_{\mathrm{d}}
$$

$\Phi_{\mathrm{f}}$ is the face VoF value, $\Phi_{\mathrm{d}}$ is the donor cell VoF value, $\beta$ is the slope limiter value and $\nabla \Phi_{\mathrm{d}}$ is the donor cell VoF gradient value. For the compressive scheme, the slope limiter value $\beta$ equals two. A detailed review of the compressive scheme is presented in [7]. The compressive scheme is computationally less expensive than the geometric reconstruction scheme, however it is also more diffusive and hence the phase interface will not be as sharp for a given calculational mesh. Due to the fact that it can be used with an implicit volume fraction discretization scheme, the applied time-step is not limited to Courant numbers less than or equal to one. This provides great potential for accelerating multiphase CFD simulations and is therefore particularly attractive for industrial applications. The accuracy of the phase interface reconstruction also strongly depends on the grid density. Fine meshes are able to resolve the phase interface better than coarse meshes.

\section{BASELINE CFD MODEL SET-UP AND RESULTS}

With the simplifying assumption that the lubricating gap height is constant around the circumference of the journal bearing, the bearing is symmetric with regards to its rotational and its vertical axis (Figure 4). In an actual journal bearing the oil is typically supplied through an axial feed groove. However, since the groove usually does not extend over the full length of the bearing, it can be assumed that, at the point where the liquid emerges from the lubricating gap into the external environment, the velocity profiles in the axial and circumferential directions are fully developed. The validity of this assumption has previously been confirmed in [4]. Figure 7 shows a schematic diagram of the boundary condition types applied to the CFD model.

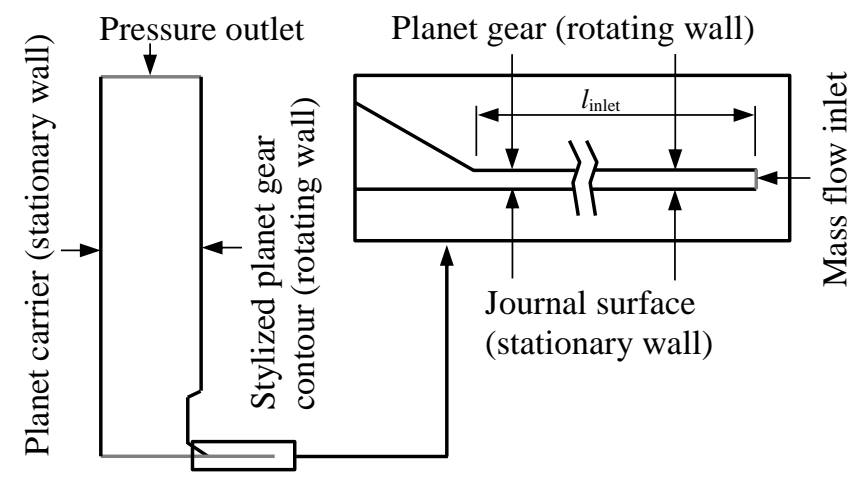

Figure 7: Schematic diagram of CFD model with boundary condition types 
The inlet length, $l_{\text {inlet }}$, chosen for the CFD model must be sufficiently large to allow the flow field to fully develop. The CFD analyses were performed with an oil viscosity which was equivalent to a temperature of $T=30{ }^{\circ} \mathrm{C}$. This temperature was used to simulate liquid properties similar to those of existing experiments and thus, enable comparison with flow behaviors observed on rotating disks and cups [9, 10, 11, 12, 13]. It should be noted that this temperature is not representative of any typical journal bearing operating temperature.

In order to establish a baseline case, a $3 \mathrm{D}$, rotationally periodic, $15^{\circ}$ sector model was created. The explicit VoF method with geometric phase interface reconstruction (Figure 6) was used to track the oil inside the domain. The fully structured computational mesh was created in a two dimensional (2D) space and subsequently rotated by $+/-7.5^{\circ}$ around the bearing's axis. The mesh consisted of $24 \mathrm{k}$ cells in each $2 \mathrm{D}$ plane. The sector, in turn, consisted of 60 equispaced planes, resulting in a total cell count of $1.42 \mathrm{M}$. At the walls, an inflation layer was applied. The height of the first cell and the inflation layer parameters were chosen such that the non-dimensional wall distance, $y^{+}$, was always smaller than 0.5 . In the region outside of the inflation layer the aim was to create regular hexahedral cells. However, as a result of using a structured mesh, some high aspect ratio cells could not be avoided. A mesh density study was carried out and is reported in [4]. The mesh density study concluded that for realistic geometry, i.e. a rounded lower gear base edge (diameter $d_{1}$ in Figure 5, Figure 8b), and oil properties and operational parameters as specified in Appendix A, Table 4, the oil flow path is independent of the chosen mesh density - providing it is within the limits investigated in [4]. A time-step of $\Delta t=2 \times 10^{-7} \mathrm{~s}$ was used. This is due to very small cell sizes required to adequately resolve the flow inside the lubricating gap. All key boundary conditions and parameter settings are listed in Annex A, Table 4. The predicted flow behavior is shown in Figure 8.
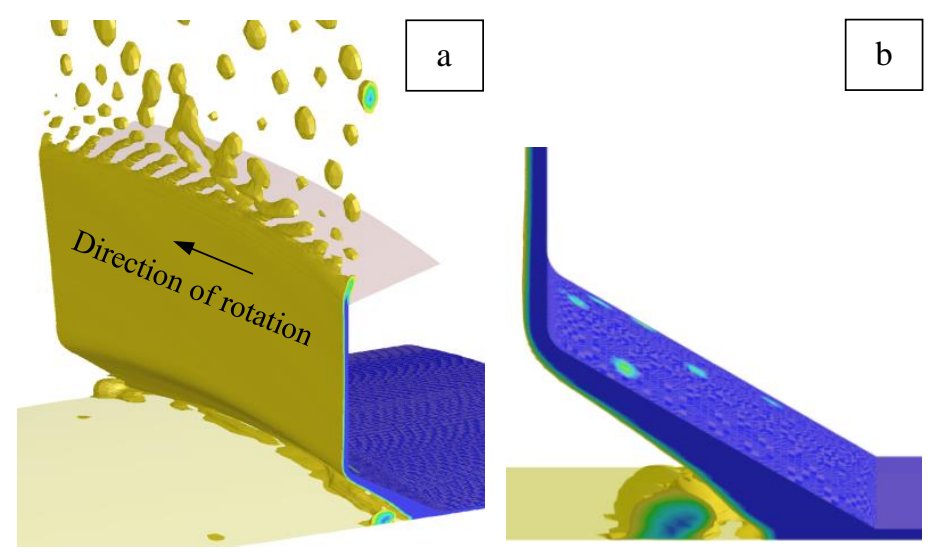

Figure 8: Baseline CFD sector model results for $\boldsymbol{T}=30{ }^{\circ} \mathrm{C}$ with boundary conditions and parameter settings as specified in Annex A, Table 4 in full (a) and detail view (b). Displayed iso-surface indicates $25 \%$ cell oil volume content.

With oil continuously entering the domain through the mass flow inlet (Figure 7), the phase interface progressively moves from the inlet boundary toward the planet carrier. When the oil exits the lubricating gap, the axial velocity reduces rapidly due to the high oil viscosity. Thus, the oil film thickness increases. In fact, the oil film thickness increases to such an extent that body forces are no longer negligible. The swirling oil is driven radially outward toward the gear chamfer. From there it follows the planet gear contour. The oil separates as a sheet which subsequently disintegrates into ligaments (Figure 8 ) and droplets. A detailed characterization of the internal and external flow is provided in [4]. The simulated oil flow path follows path $b_{2}$ in Figure 5. It is comparable to flow regimes previously observed on rotating disks [13].

\section{BASELINE CFD MODEL VALIDATION (FLOW REGIME)}

A fundamental study of oil film disintegration at the rim of a rotating disk has been performed in [13]. The configuration was an abstraction of a typical droplet generating source in a jet engine bearing chamber. Hence, both geometrical and operational conditions were similar to those of a planet gear in an epicyclic planetary gearbox. The investigations concluded that, with increasing liquid flow rate and/or increasing rotational speed of the cup, the following disintegration regimes can be observed: direct droplet formation, ligament formation, sheet formation.

Investigations carried out in [10] and later in [11] identified that the type of flow regime is dependent on the liquid volume flow rate, $\dot{V}$, the cup's angular velocity, $\Omega$, and the physical properties of the liquid - namely its viscosity, $\mu$, density, $\rho$, and surface tension, $\sigma$.

In order to allow comparison between different operating conditions, the following non-dimensional quantities were defined in [13]:

$$
\begin{gathered}
\dot{V}^{+}=\frac{\rho \dot{V}^{2}}{\sigma d^{3}} \\
O h=\frac{\mu}{\sqrt{\rho d \sigma}} \\
W e^{*}=\frac{1}{8} \frac{\rho \Omega^{2} d^{3}}{\sigma}
\end{gathered}
$$

The non-dimensional volume flow rate, $\dot{V}^{+}$, relates the liquid's density, $\rho$, and the actual volume flow rate, $\dot{V}$, to the liquid's surface tension, $\sigma$, and the disk diameter, $d$. The Ohnesorge number, $\mathrm{Oh}$, relates viscous forces to inertial and surface tension forces and the modified Weber number, $W e^{*}$, is a measure of the relative importance of the fluid's inertia compared to its surface tension. Correlations for the transition volume flow rate from direct droplet to ligament formation, $\dot{V}_{1}^{+}$, and from ligament to sheet formation, $\dot{V}_{2}^{+}$, were obtained from experimental testing [13].

$$
\begin{gathered}
\dot{V}_{1}^{+}=0.0854 O \mathrm{Oh}^{-0.9} W \mathrm{e}^{*-0.85} \\
\dot{V}_{2}^{+}=0.1378 O \mathrm{Oh}^{-0.33} W \mathrm{e}^{*-0.435}
\end{gathered}
$$


The expected flow regime can be determined by comparing the non-dimensional flow rate, $\dot{V}^{+}$(equation 3), with the transition flow rates, $\dot{V}_{1}^{+}$(equation 6) and $\dot{V}_{2}^{+}$(equation 7). For $\dot{V}^{+}<\dot{V}_{1}^{+}$direct droplet formation is expected, for $\dot{V}_{1}^{+}<\dot{V}^{+}<$ $\dot{V}_{2}^{+}$ligament formation is expected and for $\dot{\mathrm{V}}^{+}>\dot{\mathrm{V}}_{2}^{+}$sheet formation is expected.

The characteristic numbers, i.e. $\dot{V}^{+}, O h, W e^{*}$, and the transition flow rates, $\dot{V}_{1}^{+}$and $\dot{V}_{2}^{+}$, were calculated with the actual geometrical and operational values and fluid properties for the case under consideration. Table 1 provides an overview of the calculated values.

Table 1: Characteristic numbers for baseline CFD sector model for $T=30{ }^{\circ} \mathrm{C}$ with boundary conditions and parameter settings as specified in Annex A, Table 4

\begin{tabular}{|l|c|}
\hline $\begin{array}{l}\text { Non-dimensional flow rate } \dot{V}^{+} \\
\text {(equation 3) }\end{array}$ & 0.395 \\
\hline $\begin{array}{l}\text { Transition flow rate from droplet to } \\
\text { ligament formation, } \dot{V}_{1}^{+} \text {(equation 6) }\end{array}$ & $5.06 \times 10^{-6}$ \\
\hline $\begin{array}{l}\text { Transition flow rate from ligament to } \\
\text { sheet formation, } \dot{V}_{2}^{+} \text {(equation 7) }\end{array}$ & $5.69 \times 10^{-4}$ \\
\hline Result & $\dot{V}^{+}>\dot{V}_{2}^{+}$ \\
\hline Predicted flow regime & Sheet formation \\
\hline
\end{tabular}

The predicted flow regime based on the work of [13], i.e. sheet formation, is consistent with the result from the baseline CFD sector model (Figure 8).

The liquid disintegration modes observed on rotating cups are similar to those observed on rotating disks. However, the flow conditions at which the disintegration mode changes from droplet to ligament formation and from ligament to sheet formation are different. In contrast to a rotating disk, a rotating cup exhibits less slip between the bulk flow of the liquid and the rotating surface. Hence, the transition from one disintegration mode to another occurs at lower Weber numbers.

\section{BASELINE CFD MODEL VALIDATION (FLOW PATH)}

A mesh dependency study reported in [4] highlighted that, under certain conditions, the oil film does not separate from the upper edge of the gear base (diameter $d_{2}$ in Figure 5), as shown in Figure 8, but from the lower edge of the gear base (diameter $d_{1}$ in Figure 5). This phenomenon occurred particularly when sharp-edged geometry was used.

The change of flow path direction from the gear chamfer to the vertical surface of the gear base (Figure 5) is comparable to the change of flow path direction over an inclined step. Shear driven flows over an inclined step were investigated in [14], in which a separation criterion was established to predict the conditions under which flows attach to, or separate from, the surface of an inclined step. The separation criterion is based on a force balance, which accounts for oil film inertia, surface tension and gravitational effects. The force balance model proposed in [14] was modified to make it applicable to the case under consideration (Figure 9).

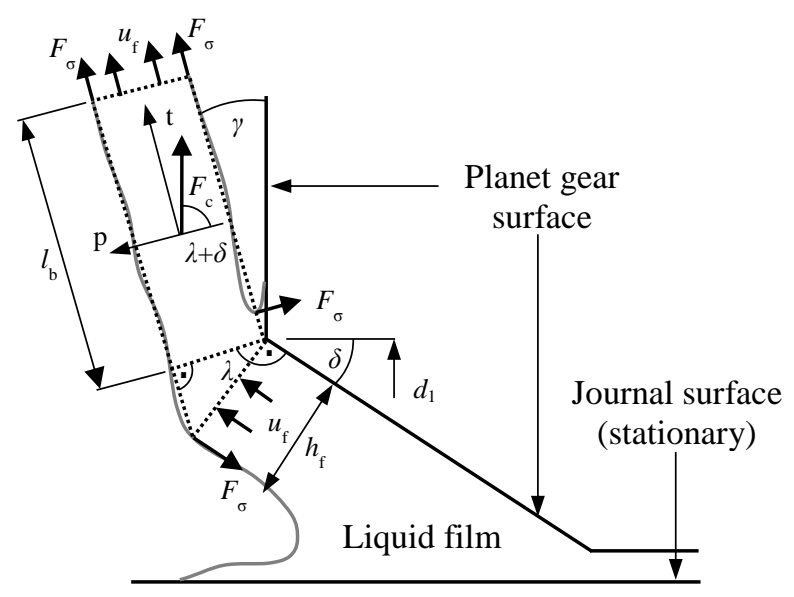

Figure 9: Force balance on oil film control volume upon separation from the lower edge of the gear base, $d_{1}$

In order to conserve the linear momentum of the oil film in p-direction, the following equation, which balances inertial, surface tension and gravitational forces (Figure 9), applies.

$$
\begin{aligned}
& \rho_{\mathrm{f}} u_{\mathrm{f}}^{2} h_{\mathrm{f}} \sin \lambda=\sigma \sin \lambda+\sigma \\
& +\rho_{\mathrm{f}} h_{\mathrm{f}} l_{\mathrm{b}} \Omega^{2} \frac{d_{1}}{2} \cos (\lambda+\delta)
\end{aligned}
$$

In the above equation, $\rho_{\mathrm{f}}$ is the density of the fluid, $u_{\mathrm{f}}$ is the velocity of the fluid, $h_{\mathrm{f}}$ is the fluid film thickness, $\lambda$ is the angle describing the change of flow path direction, $\sigma$ is the surface tension, $\Omega$ is the angular velocity of the gear, $d_{1}$ is the diameter at which oil separation occurs, $\delta$ is the gear chamfer angle and $l_{\mathrm{b}}$ is the characteristic break-up length of the sheet from the edge where it separates from the gear to the point of disintegration. Due to conservation of mass, $u_{\mathrm{f}}$ and $h_{\mathrm{f}}$ are interdependent.

As the gear chamfer replicates the geometry of a rotating cup, the fluid velocity, $u_{\mathrm{f}}$, and film thickness, $h_{\mathrm{f}}$, can be determined from the following equations according to [10].

$$
\begin{gathered}
u_{\mathrm{f}}=\left(\frac{2 \dot{V}^{2} n^{2} \sin \delta}{3 d v}\right)^{\frac{1}{3}} \\
h_{\mathrm{f}}=\left(\frac{3 \dot{V} v}{2 \pi^{3} d^{2} n^{2} \sin \delta}\right)^{\frac{1}{3}}
\end{gathered}
$$

In the above equations, $\dot{V}$ is the volumetric flow rate of the liquid, $n$ is the rotational speed of the cup, $\delta$ is the opening angle of the cup, i.e. the gear chamfer angle, $d$ is the cup diameter and $v$ is the kinematic viscosity of the liquid.

In order to determine the break-up length, $l_{\mathrm{b}}$, for their investigations on the separation of shear-driven films, [14] used an existing experimental correlation which was established in [15]. However, this correlation does not apply to rotating or swirling flows as observed on spinning cups or disks. As shown in Figure 10, for flow over rotating cups, there are two distinct 
sheet disintegration mechanisms, namely combined wave and rim disintegration (Figure 10a) and wave disintegration (Figure 10b).

The break-up length depends on the disintegration regime. It has been identified in [9] that the dominant parameter affecting the mechanism of sheet disintegration is the peripheral speed of the cup. For peripheral speeds larger than $8 \mathrm{~m} / \mathrm{s}$ wave disintegration occurs. Since the peripheral speed of the planet gear at the location of sheet separation (diameter $d_{1}$ in Figure 5) is many times larger than the limit established in [9], the prevailing sheet disintegration mechanism for the case under consideration is wave disintegration (Figure 10b and Figure 8). The break-up length can be calculated from

$$
l_{\mathrm{b}}^{2}=31.5 \times 10^{4} v_{\text {rat }}^{0.25} \frac{\left(\sigma \dot{m}_{\mathrm{f}}\right)^{\frac{2}{3}}}{\left(n d_{1}\right)^{2}}+0.6
$$

In the above equation, $v_{\text {rat }}$ is the kinematic viscosity ratio of oil and water, $\dot{m}_{\mathrm{f}}$ is the liquid mass flow rate, $n$ is the rotational speed of the cup and $d_{1}$ is the diameter at which oil separation occurs (Figure 9).
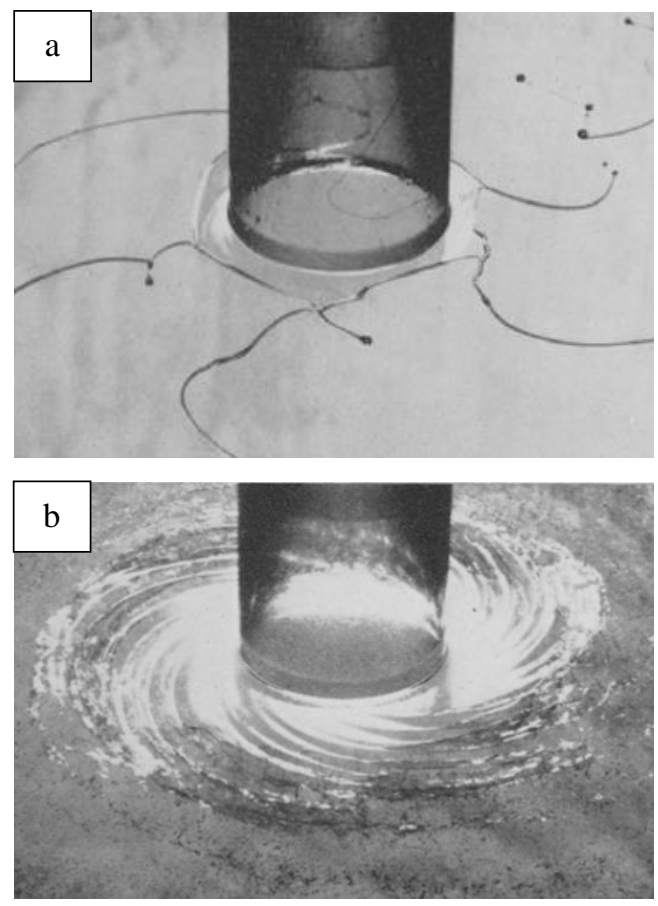

Figure 10: Combined wave and rim disintegration a) and wave disintegration b) according to [9]

When comparing Figure 8 and Figure 10b, it can be observed that the radial extent of the sheet in Figure 8 is much smaller than that in Figure 10b. This is due to the much higher peripheral speed of the planet gear at the location of sheet separation compared to the rotating cup used in [9]. This reduces the radial extent of the sheet (equation 11).

Having established the break-up length, $l_{\mathrm{b}}$, equations 8,9 , 10 and 11 can be combined to determine the angular change of direction, $\lambda$, of the liquid after separating from the lower edge of the gear base (diameter $d_{1}$ in Figure 9). For maximum takeoff (MTO) conditions, with all boundary conditions and parameter settings as specified in Appendix A, Table $4, \lambda$ is calculated to be $59.6^{\circ}$. Hence, the angle between the liquid sheet and the vertical gear face, $\gamma$, is $0.4^{\circ}$ (Figure 9). Therefore, in practical terms, it can be assumed that the oil film attaches to the vertical surface of the gear and separates from the upper edge of the gear base (diameter $d_{2}$ in Figure 5). The results from the analyses of the force balance model are therefore consistent with the CFD model predictions shown in Figure 8.

\section{CFD MODEL VALIDATION (OIL FILM THICKNESS)}

As highlighted in the previous section, the oil film thickness on a rotating cup can be calculated from equation 10 . In order to validate the CFD model results against a representative oil film thickness measurement, it must be ensured that the oil film on the gear chamfer (Figure 5) is fully developed. As shown in Figure 8b, for an oil feed mass flow rate equivalent to MTO conditions, the length of the gear chamfer is insufficient for the oil film to fully develop. This is indicated by the wedge shape of the oil film (Figure 8b). Therefore, with otherwise identical boundary conditions, an additional case was set up with a $33 \%$ reduced oil feed mass flow rate compared to MTO conditions. This allowed the oil film thickness along the gear chamfer to fully develop. Thus, oil film thickness measurements in the CFD model are more representative when compared to existing data. The oil film thickness was determined at the location shown in Figure 11.

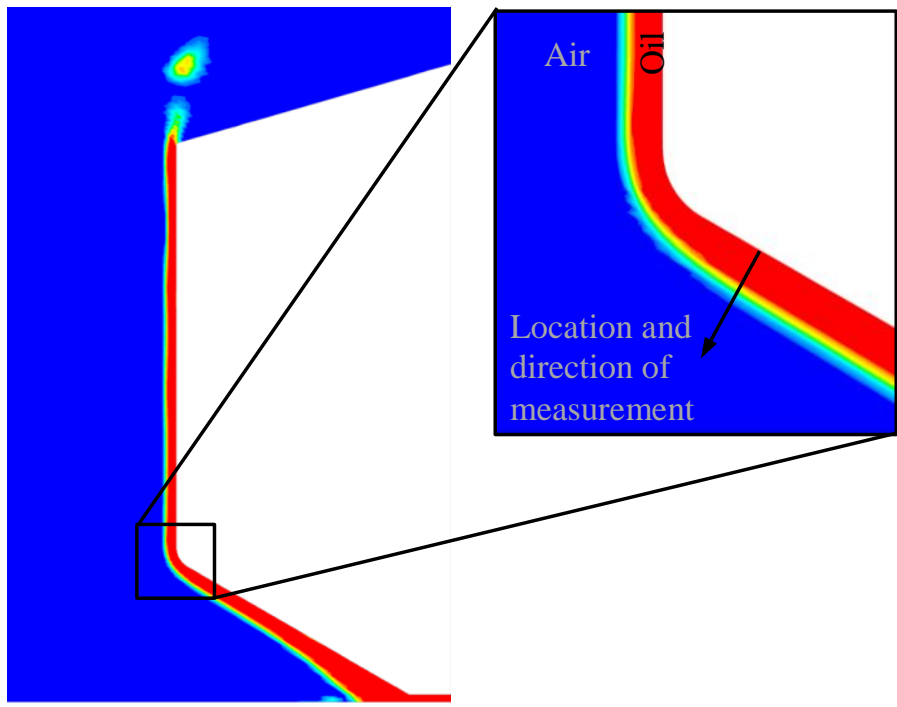

Figure 11: Oil film thickness measurement location and direction with $\dot{m}_{\mathrm{f}}=0.66 \dot{m}_{\mathrm{f}, \mathrm{MTO}}$

When using the VoF method, it is commonly accepted practice to determine oil film thicknesses at an oil volume fraction of $50 \%$ - provided a reasonably sharp interface has been resolved. A comparison of the normalized oil film 
thicknesses for the baseline model with different oil feed mass flow rates and rotational speeds is presented in Table 2. The normalized oil film thickness $H_{\mathrm{f}}$ in Table 2 was determined by measuring the oil film thickness in the CFD model according to Figure 11 and normalizing it by the calculated value according to equation 10 .

Table 2: Comparison of measured and calculated oil film thickness for baseline model

\begin{tabular}{|l|c|}
\hline Operating condition & $\begin{array}{c}\text { Normalized oil film } \\
\text { thickness } H_{\mathrm{f}}[-]\end{array}$ \\
\hline$\dot{m}_{\mathrm{f}}=0.66 \dot{m}_{\mathrm{f}, \mathrm{MTO}}, \Omega=\Omega_{\mathrm{MTO}}$ & 1.007 \\
\hline$\dot{m}_{\mathrm{f}}=0.33 \dot{m}_{\mathrm{f}, \mathrm{MTO}}, \Omega=\Omega_{\mathrm{MTO}}$ & 1.033 \\
\hline$\dot{m}_{\mathrm{f}}=0.33 \dot{m}_{\mathrm{f}, \mathrm{MTO}}, \Omega=0.66 \Omega_{\mathrm{MTO}}$ & 1.012 \\
\hline Difference $\Delta H[\%]$ & $0.7 \ldots 3.3$ \\
\hline
\end{tabular}

There is a very good agreement between the measured oil film thickness in the CFD model and the calculated oil film thickness for the operating points under consideration. The oil film thickness determined from the CFD model deviates between $0.7 \%$ and $3.3 \%$ from the calculated value according to equation 10 .

\section{GEOMETRICAL VS COMPRESSIVE PHASE INTERFACE RECONSTRUCTION}

As previously highlighted, in contrast to the geometric phase interface reconstruction scheme, the compressive scheme available in ANSYS Fluent [1] can be used with implicit volume fraction discretization. This provides a great potential for reducing the computational time required for transient multiphase CFD analysis. This reduction is achieved by increasing the time-step, $\Delta t$.

The following figures illustrate how, compared to the baseline model (Figure 8, Figure 12a), an increased time-step affects the CFD simulation results in steady state conditions, i.e. at an elapsed flow time of $t=0.02 \mathrm{~s}$, with respect to the phase interface resolution. For all simulations, the mesh from the baseline case, i.e. a total cell count of $1.42 \mathrm{M}$, was used. All other boundary conditions and parameter settings are specified in Appendix A, Table 4. The displayed iso-surface indicates $25 \%$ cell oil volume content. All simulations were run on a high performance computer (HPC), using 144 processing cores.

As shown in Figure 12 to Figure 15, the choice of the phase interface reconstruction scheme does not affect the flow path prediction. For both phase interface reconstruction schemes, i.e. the geometric and the compressive scheme, and for all chosen time-steps, the simulated oil flow path follows path $b_{2}$ in Figure 5. Figure 12a shows highly resolved liquid sheet disintegration into ligaments and droplets. Qualitatively, the simulated flow structures are similar to those prevailing on rotating cups [9] (Figure 10b). Although predicting the same flow path, the compressive scheme is generally unable to resolve detailed flow structures like droplets and ligaments, which is due to the fact that the compressive scheme is more diffusive than the geometric reconstruction scheme.
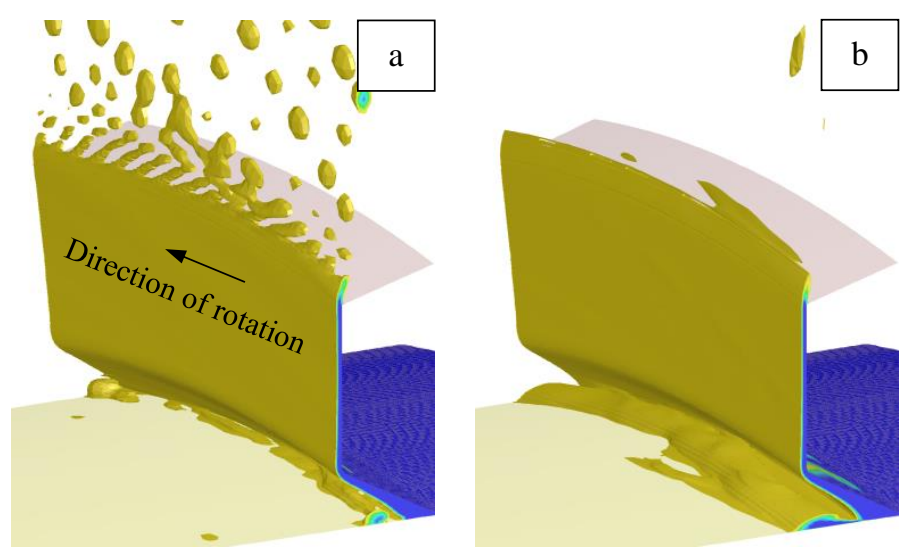

Figure 12: Geometric (a) and compressive, explicit (b) phase interface reconstruction with $\Delta t=2 \times 10^{-7} \mathrm{~s}$
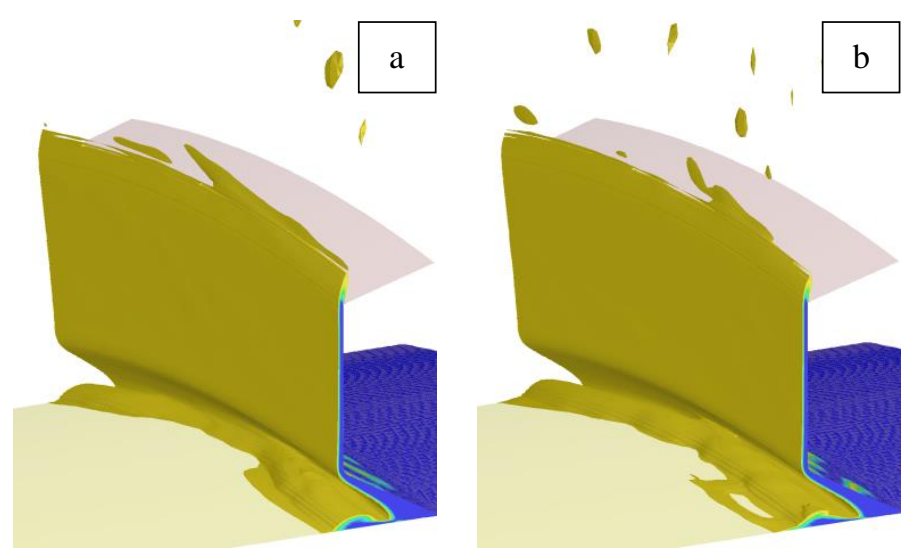

Figure 13: Compressive, implicit phase interface reconstruction with $\Delta t=2 \times 10^{-7} \mathrm{~s}$ (a) and $\Delta t=5 \times 10^{-7} \mathrm{~s}$ (b)
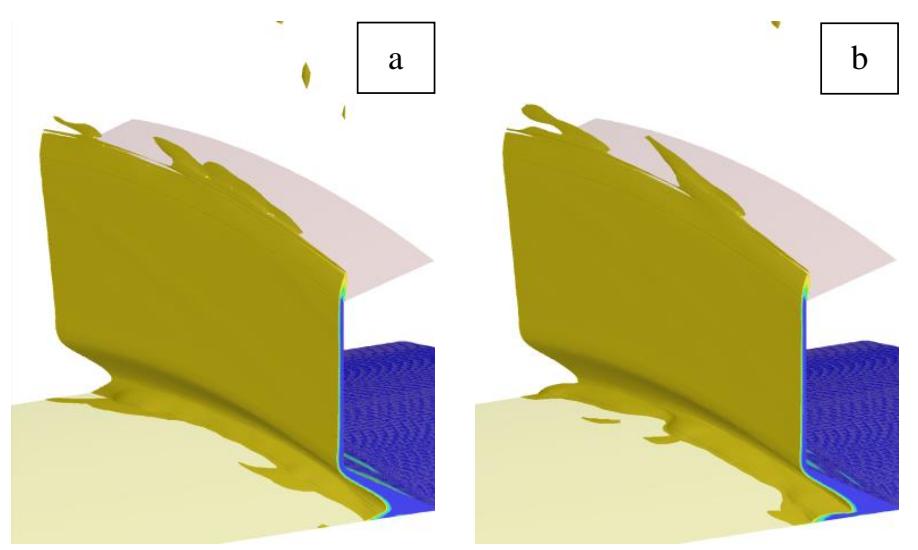

Figure 14: Compressive, implicit phase interface reconstruction with $\Delta t=1 \times 10^{-6} \mathrm{~s}$ (a) and $\Delta t=5 \times 10^{-6} \mathrm{~s}$ (b) 


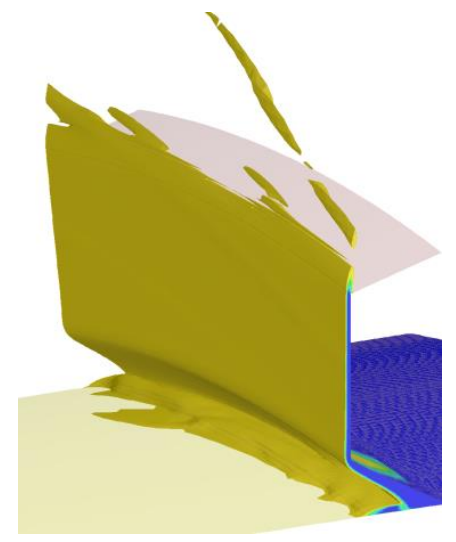

Figure 15: Compressive, implicit phase interface reconstruction with $\Delta t=1 \times 10^{-5} \mathrm{~s}$

For the case under consideration, increasing the time-step by a factor of 50 does not noticeably affect the resolution and the level of detail captured with the compressive interface reconstruction scheme. If general information about the oil flow path behavior are of interest, the compressive scheme should be chosen as higher time-steps allow a significant reduction of the overall computational time. However, if the resolution of detailed flow structures and characteristics are of primary interest, the compressive scheme may not be able to capture those without increasing the cell count of the calculational mesh. In this case it is recommended that a geometric phase interface reconstruction should be used. It should be noted that the statements made above are not only applicable to radial oil outflow, i.e. flow path $\mathrm{b}$ in Figure 5, but also to axial oil outflow, i.e. flow path a in Figure 5, as reported in [4].

Table 3 lists the corresponding computing times required to simulate an elapsed flow time of $t=0.02 \mathrm{~s}$.

Table 3: Comparison of computing times required to simulate an elapsed flow time of $t=0.02 \mathrm{~s}$ for different phase interface reconstruction schemes, discretization schemes and time-steps

\begin{tabular}{|c|c|c|c|c|c|}
\hline $\begin{array}{c}\text { Phase } \\
\text { interface } \\
\text { recon- } \\
\text { struction }\end{array}$ & $\begin{array}{c}\text { Discre- } \\
\text { tization } \\
\text { scheme }\end{array}$ & $\begin{array}{c}\text { Time- } \\
\text { step } \Delta t \\
{[\mathrm{~s}]}\end{array}$ & $\begin{array}{c}\text { Compu- } \\
\text { ting time } \\
{[\mathrm{min}]}\end{array}$ & $\begin{array}{c}\text { Max. } \\
C\end{array}$ & $\begin{array}{c}\text { Norma- } \\
\text { lized oil } \\
\text { film thick- } \\
\text { ness } H_{\mathrm{f}}[-]\end{array}$ \\
\hline Geo. & Explicit & $2 \times 10^{-7}$ & 6220 & 0.4 & 1.000 \\
\hline Comp. & Explicit & $2 \times 10^{-7}$ & 7514 & 0.4 & 1.061 \\
\hline Comp. & Implicit & $2 \times 10^{-7}$ & 8396 & 0.4 & 1.061 \\
\hline Comp. & Implicit & $5 \times 10^{-7}$ & 5006 & 1.0 & 1.076 \\
\hline Comp. & Implicit & $1 \times 10^{-6}$ & 2575 & 2.0 & 1.058 \\
\hline Comp. & Implicit & $5 \times 10^{-6}$ & 554 & 10.0 & 1.076 \\
\hline Comp. & Implicit & $1 \times 10^{-5}$ & 270 & 20.0 & 1.031 \\
\hline
\end{tabular}

As shown in Table 3, a significant overall reduction $(-95.7 \%)$ in the computational time required to simulate an elapsed flow time of $t=0.02 \mathrm{~s}$ can be achieved by using the implicit compressive phase interface reconstruction scheme, compared to the baseline settings with the geometric phase interface reconstruction. It should be noted that for a given time-step the explicit geometric scheme is faster than the explicit and the implicit compressive scheme. This is due to a better convergence behavior of the explicit geometric reconstruction scheme, i.e. very few iterations per time-step are required to satisfy the convergence criteria. In contrast, for a given time-step, i.e. $\Delta t=2 \times 10^{-7} \mathrm{~s}$, the implicit compressive scheme requires more iterations per time-step to meet the convergence criteria than the explicit compressive scheme, which, in turn, requires more iterations per time-step to meet the convergence criteria than the explicit geometric reconstruction scheme. As previously noted, less computational time is required for a single iteration when using the compressive scheme compared to the explicit geometric reconstruction scheme. However, this benefit is negated by the poorer convergence behavior. If the chosen time-step is sufficiently large, i.e. $\Delta t \geq 5 \times 10^{-7} \mathrm{~s}$, the convergence behavior degrades such that the specified maximum number of iterations per time-step is reached before the convergence criteria are met. Under these conditions the computational time required to simulate an elapsed flow time of $t=0.02 \mathrm{~s}$ scales well with the chosen time-step. When considering the use of the compressive scheme for accelerating the computational time required to simulate a certain elapsed flow time, the poorer convergence behavior should be taken into account.

The normalized oil film thickness, $H_{\mathrm{f}}$, in Table 3 has been determined by measuring the oil film thickness according to Figure 11 and normalizing it by the oil film thickness obtained with an explicit geometric phase interface reconstruction and a time-step of $\Delta t=2 \times 10^{-7} \mathrm{~s}$. The oil film thickness, $h$, is independent of the chosen time-step $\Delta t$. Compared to a geometric phase interface reconstruction, the predicted oil film thickness is slightly higher when a compressive phase interface reconstruction is used.

\section{INLET BOUNDARY CONDITIONS FOR MODELING EXTERNAL OIL FLOW FROM AN ECCENTRIC JOURNAL BEARING}

As a result of external forces, journal bearings develop an eccentricity between the pin and the bush axis. As a consequence, a convergent-divergent lubricating gap is created (Figure 16).

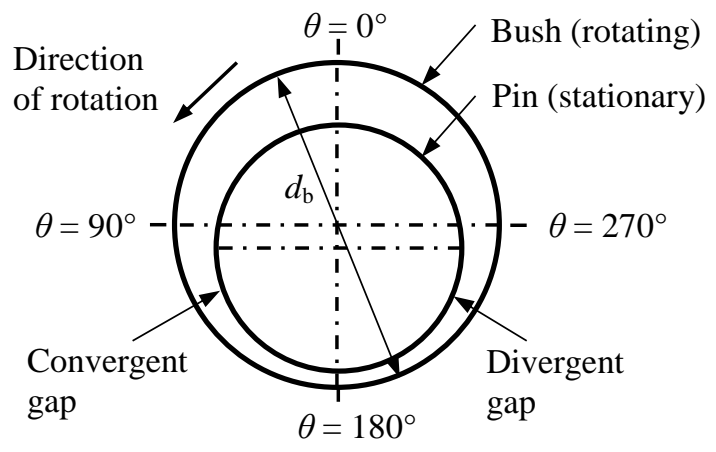

Figure 16: Schematic diagram of journal bearing 
The resultant pressure field in the lubricating film generates a force equal and opposite to the external force acting on the bearing. Due to this pressure field, the outflow behavior of an eccentric journal bearing will be different compared to that of a concentric journal bearing.

In order to correctly predict the outflow behavior of an eccentric journal bearing, it is crucial to apply an adequate inlet boundary condition. Naturally, the inlet boundary condition for the external flow domain is determined by the outlet condition of the internal flow domain. Internal journal bearing flow has been widely discussed in the literature. Examples are given in $[16,17]$ and [18]. According to [16], in lubrication theory, the following five key simplifying assumptions are valid for the majority of applications.

a) The fluid is assumed to be Newtonian.

b) Inertia and body force terms are assumed to be negligible compared to viscous terms.

c) Negligibly small variation of pressure across the film.

d) The flow is laminar.

e) Curvature effects are negligible.

Applying the above simplifying assumptions to the NavierStokes equations reduces them to the Reynolds equation. For most engineering problems, it is sufficient to solve the Reynolds equation to appropriately characterize the pressure field in the lubricating film of journal bearings. Analytical solutions for the Reynolds equation only exist for infinitely short approximations (ISA) and infinitely long approximations (ILA) of journal bearings. For preliminary design purposes, a journal bearing can be considered infinitely short when the length to diameter ratio is smaller than 0.5 , and infinitely long when the length to diameter ration is larger than two [16]. If a journal bearing does neither satisfy either of these criteria, the pressure field needs to be determined by numerically solving the Reynolds equation. This is typically done by using a finite difference method (FDM).

Particularly at high eccentricities, the pressure in the divergent part of the lubricating gap can reduce to the point at which cavitation occurs. Two types of cavitation are encountered in liquid-film bearings [16]. Gaseous cavitation, for example, occurs when air, which is dissolved in the lubricant, comes out of solution, expands and forms bubbles as the film pressure drops below the saturation value. This type of cavitation is typically encountered by statically loaded journal bearings like the one under consideration. Vapor cavitation occurs when vapor is being formed due to the film pressure dropping below the lubricant's vapor pressure. This type of cavitation is typically encountered by dynamically loaded journal bearings.

A journal bearing model was set up with the commercial multiphysics software package COMSOL [19]. No oil feed was included in order to better show the fundamental differences between journal bearings with and without cavitation. The ambient pressure, $p_{\mathrm{amb}}$, was set to zero. Figure 17 and Figure 18 show a typical circumferential and axial pressure distribution with and without cavitation, normalized to the peak pressure with cavitation.

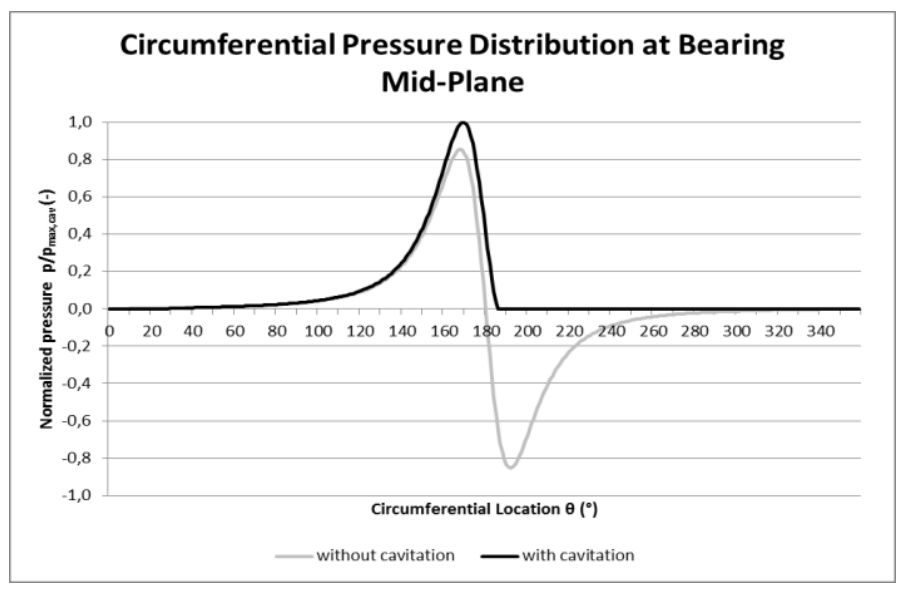

Figure 17: Normalized circumferential pressure distribution at bearing mid-plane with and without cavitation

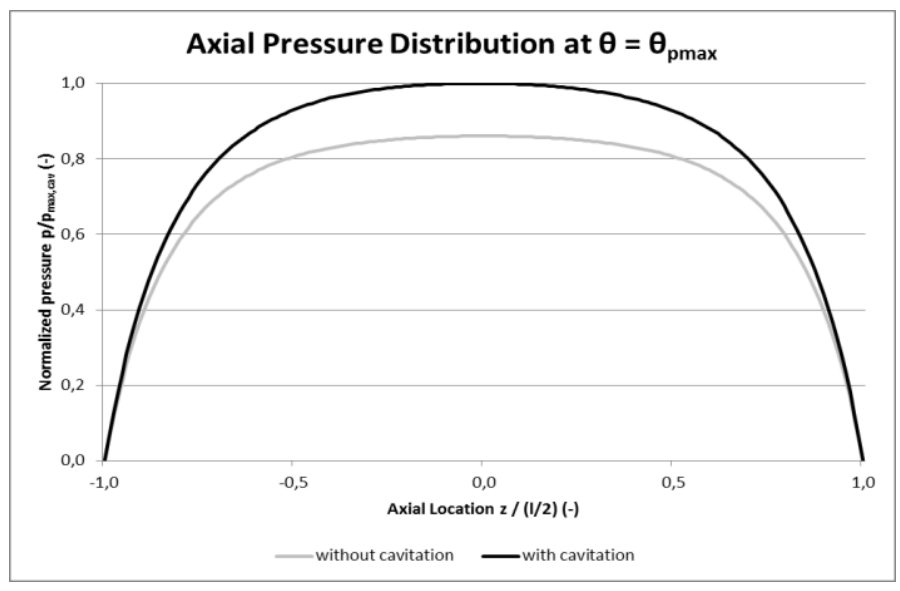

Figure 18: Normalized axial pressure distribution at $\theta=$ $\theta_{\text {pmax }}$ with and without cavitation

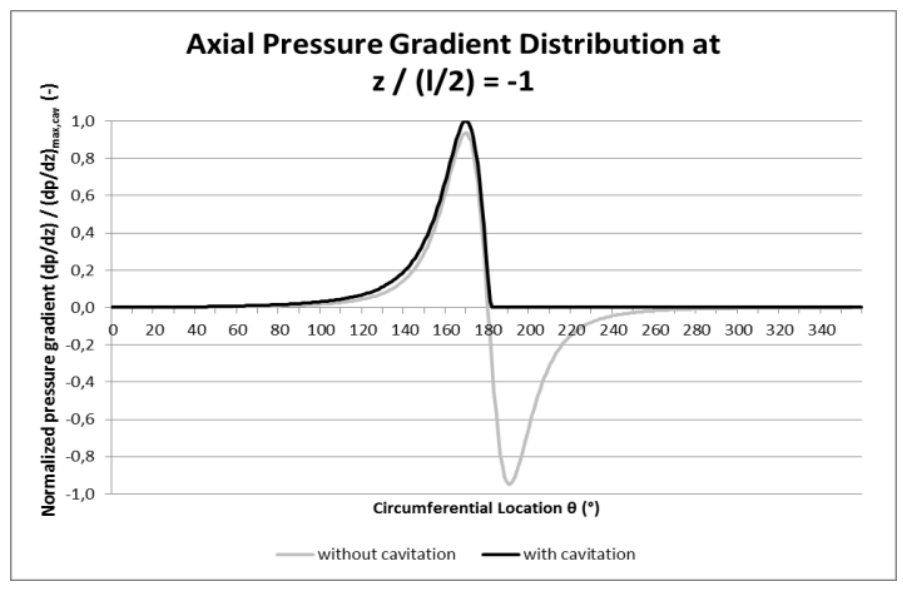

Figure 19: Normalized axial pressure gradient distribution at $z /(l / 2)=-1$ with and without cavitation 
With a known pressure field, the pressure gradient in the axial direction can be determined at any axial location, $z$. When analyzing journal bearing outflow, i.e. the flow passing through the side faces of the journal bearing, the axial pressure gradient at locations $z /(l / 2)=-1 ; 1$ is of particular importance as it drives the liquid outward. The distribution of the axial pressure gradient, $\partial p / \partial z$, around the circumference of the bearing at location $z /(l / 2)=-1$ is shown in Figure 19.

With a known axial pressure gradient around the circumference of the bearing, the axial velocity can be determined from the Reynolds equation as follows [16]. A Poiseuille flow profile develops.

$$
u_{\mathrm{ax}}=\frac{1}{2 \mu} \frac{\partial p}{\partial z}\left(i^{2}-i h\right)
$$

In the above equation, $u_{\mathrm{ax}}$ is the axial velocity, $\mu$ is the dynamic oil viscosity, which, for the sake of convenience, is assumed to be constant, $\partial p / \partial z$ is the pressure gradient in the axial direction (Figure 19) and $i$ is the radial coordinate across the lubricating gap height, $h$. It takes the value $i=0$ on either the pin or the bush surface and the value $i=h$ on the opposite surface (Figure 16). The mean axial velocity can be obtained from integrating equation 12 across the gap height.

$$
u_{\mathrm{ax}, \text { mean }}=\frac{1}{h} \frac{1}{12 \mu} \frac{\partial p}{\partial z} h^{3}
$$

According to [16], the lubricating gap height, $h$, can be approximated from the following equation.

$$
h=C_{0}+e \cos \theta
$$

In the above equation, $C_{0}$ is the radial clearance between the pin and the bush, $e$ is the eccentricity, i.e. the offset between pin and bush axis, and $\theta$ is the circumferential location. The mean axial velocity distribution at location $z /(l / 2)=-1$ is shown in Figure 20.

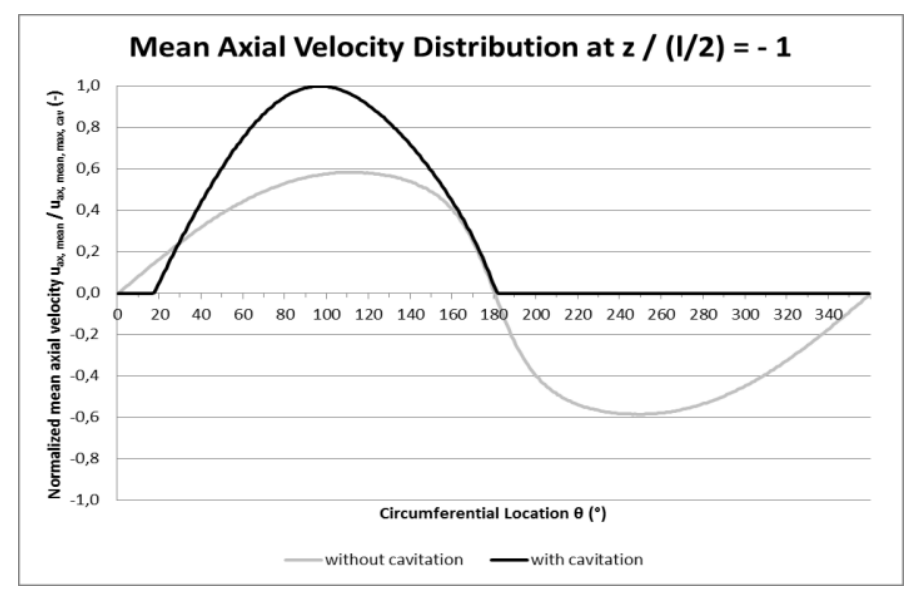

Figure 20: Normalized mean axial velocity distribution at $z$ / $(l / 2)=-1$ with and without cavitation

As shown in Figure 20, without cavitation, the mean axial velocity can take negative values in the divergent part of the lubricating gap. This indicates that axial inflow occurs in order to satisfy continuity. In contrast, with cavitation, all outflow occurs in the convergent part of the lubricating gap up to the circumferential location, $\theta_{\text {cav }}$, where the film pressure drops to the saturation pressure, $p_{\text {sat }}$. This pressure is equal or just below the ambient atmospheric pressure [17]. Thus, no or a negligibly small axial pressure gradient $\partial p / \partial z$ is present. Hence, the axial velocity within the cavitation region is zero or close to zero.

It should be noted that in addition to the axial velocity component, the oil flow emerging from the lubricating gap into the external environment also has a circumferential velocity component. The film pressure at the axial locations of $z /(l / 2)=-$ 1 ; 1 takes the constant value of the ambient pressure, $p_{\text {amb }}$. Thus, the pressure gradient in the circumferential direction at $z /(l / 2)=-1 ; 1$ is zero. Consequently, the circumferential velocity component is only determined by the rotating motion (shearing) of the bush. A Couette flow profile develops.

$$
u_{\text {circ }}=\frac{i}{h} \Omega \frac{d_{\mathrm{b}}}{2}
$$

In the above equation, $i$ is the radial coordinate across the lubricating gap height, $h, \Omega$ is the rotational speed of the bush and $d_{\mathrm{b}}$ is the bush diameter. The mean circumferential velocity is constant around the bearing's circumference and equal to half the rotational speed of the bush.

$$
u_{\text {circ,mean }}=\Omega \frac{d_{\mathrm{b}}}{4}
$$

The profiles for the axial and circumferential velocity distributions across the lubricating gap height, $h$, and around the bearing's circumference (equations 12 and 15) can be used as a boundary condition for a CFD model to simulate external oil flow from an eccentric journal bearing. This has the advantage that modeling internal journal bearing flow in order to obtain these boundary conditions can be avoided. CFD modeling of internal journal bearing flow is complex due to the large differences in length scales, which can lead to adverse cell aspect ratios. Particularly when including cavitation phenomena, a computationally expensive, transient multiphase model is required. Avoiding this dramatically reduces the overall analysis time.

\section{CONCLUSIONS}

The analyses carried out allow the following key conclusions to be drawn.

a) The geometric phase interface reconstruction scheme is able to resolve detailed flow structures, such as ligaments and droplets. Qualitatively and quantitatively the simulated flow behavior is consistent with observations made on liquid flow over rotating cups and disks.

b) The compressive phase interface reconstruction scheme fails to resolve detailed flow structures such as ligaments and droplets.

c) The flow path prediction, i.e. radial outflow according to flow path $b_{2}$ in Figure 5, is independent of the chosen 
phase interface reconstruction scheme and the range of time-steps investigated for the case under consideration.

d) When considering the use of the compressive scheme for accelerating the computational time required to simulate a certain elapsed flow time, the convergence behavior of both interface reconstruction schemes must be considered. Changing from geometric to compressive phase interface reconstruction may not reduce the computational time required to simulate a certain elapsed flow time if the time-step remains unchanged.

e) If the accuracy of the compressive face interface reconstruction is deemed acceptable, a significant reduction in computational time required to simulate a certain elapsed flow time can be achieved by increasing the time-step.

f) The Reynolds equations approach provides an appropriate method for defining accurate inlet boundary conditions for the simulation of external oil flow from an eccentric journal bearing. This avoids CFD modeling of internal journal bearing flow.

\section{OUTLOOK}

The future objective is to create a design tool for routine use and provide accurate boundary conditions for a larger CFD model to simulate the oil scavenge behavior inside a planetary gearbox. In order to achieve this objective, the method of generating an accurate inlet boundary condition for simulating external oil flow from an eccentric journal bearing will be applied to a CFD model. Based on the findings from the analysis presented in the first part of this contribution, an implicit compressive phase interface reconstruction scheme will be used. With a robust CFD model in place, external journal bearing oil flow will be assessed with and without orbiting motion. At this stage, the model fidelity will have increased to fully represent a true journal bearing.

Experimental rig testing is planned to be carried out in order to validate the simplified CFD model with an axially and circumferentially constant lubricating gap height, $h$.

\section{ACKNOWLEDGMENTS}

This work has been carried out in collaboration with RollsRoyce plc and is part of the Aerospace Technology Institute (ATI) MAMOTH research program. Rolls-Royce plc's permission to publish this work is greatly appreciated. The authors additionally acknowledge the support by ANSYS Inc. Very valuable support has been provided by the University of Nottingham's Gas Turbine and Transmissions Research Centre (G2TRC), the Fluids and Thermofluids Departments of RollsRoyce plc and Rolls-Royce Deutschland Ltd \& Co KG, and the Structures and Transmissions Department of Rolls-Royce plc. The authors are grateful for access to the University of Nottingham High Performance Computing Facility.

\section{NOMENCLATURE}

\begin{tabular}{|c|c|}
\hline ATI & Aerospace Technology Institute \\
\hline CFD & Computational Fluid Dynamics \\
\hline DPM & Discrete Phase Model \\
\hline FDM & Finite Differences Method \\
\hline G2TRC & Gas Turbines and Transmissions Research Centre \\
\hline $\mathrm{HPC}$ & High Performance Computer \\
\hline ILA & Infinitely Long Approximation \\
\hline ISA & Infinitely Short Approximation \\
\hline LS & Level-Set \\
\hline MTO & Maximum Take-Off \\
\hline PLIC & Piecewise Linear Interface Construction \\
\hline SPH & Smoothed Particle Hydrodynamics \\
\hline SST & Shear Stress Transport \\
\hline UTC & University Technology Centre \\
\hline VoF & Volume of Fluid \\
\hline$A$ & Area $\left[\mathrm{m}^{2}\right]$ \\
\hline$C$ & Courant number $[-]$ \\
\hline$C_{0}$ & Radial clearance $[\mathrm{m}]$ \\
\hline$d$ & Diameter $[\mathrm{m}]$ \\
\hline$e$ & Eccentricity $[\mathrm{m}]$ \\
\hline$F_{\mathrm{c}}$ & Centrifugal force $[\mathrm{N}]$ \\
\hline$F_{\text {tan }}$ & Tangential gear force $[\mathrm{N}]$ \\
\hline$F_{\sigma}$ & Surface tension force $[\mathrm{N}]$ \\
\hline$h$ & Lubricating gap height $[\mathrm{m}]$ \\
\hline$h_{\mathrm{f}}$ & Film height $[\mathrm{m}]$ \\
\hline$H_{\mathrm{f}}$ & Relative film height [-] \\
\hline$i$ & Radial coordinate across gap height [m] \\
\hline$k$ & Turbulent kinetic energy $[\mathrm{J} / \mathrm{kg}]$ \\
\hline$l$ & Length $[\mathrm{m}]$ \\
\hline$l_{\mathrm{b}}$ & Break-up length $[\mathrm{m}]$ \\
\hline$\dot{m}_{\mathrm{f}}$ & Film mass flow rate $[\mathrm{kg} / \mathrm{s}]$ \\
\hline$n$ & Rotational speed [rev/s] \\
\hline $\mathrm{Oh}$ & Ohnesorge number [-] \\
\hline$p_{\text {amb }}$ & Ambient pressure $[\mathrm{Pa}]$ \\
\hline$p_{\max }$ & Maximum pressure $[\mathrm{Pa}]$ \\
\hline$p_{\text {sat }}$ & Saturation pressure $[\mathrm{Pa}]$ \\
\hline$r$ & Radius $[\mathrm{m}]$ \\
\hline$T$ & Temperature $\left[{ }^{\circ} \mathrm{C}\right]$ \\
\hline$t$ & Time $[\mathrm{s}]$ \\
\hline$u$ & Liquid velocity $[\mathrm{m} / \mathrm{s}]$ \\
\hline$u_{\mathrm{f}}$ & Film velocity $[\mathrm{m} / \mathrm{s}]$ \\
\hline$\dot{V}$ & Oil volume flow rate $\left[\mathrm{m}^{3} / \mathrm{s}\right]$ \\
\hline$\dot{V}^{+}$ & Non-dimensional oil volume flow rate [-] \\
\hline$\dot{V}_{1}^{+}$ & $\begin{array}{l}\text { Non-dimensional transition oil volume flow rate } \\
\text { from direct droplet to ligament formation [-] }\end{array}$ \\
\hline$\dot{V}_{2}^{+}$ & $\begin{array}{l}\text { Non-dimensional transition oil volume flow rate } \\
\text { from ligament to sheet formation [-] }\end{array}$ \\
\hline$W e^{*}$ & Modified Weber number [-] \\
\hline$z$ & Coordinate of position [m] \\
\hline$\alpha_{\mathrm{q}}$ & Volume fraction [-] \\
\hline$\beta$ & Slope limiter value [-] \\
\hline$\gamma$ & Angle between liquid flow path and vertical $\left[{ }^{\circ}\right]$ \\
\hline
\end{tabular}




\section{REFERENCES}

[1] ANSYS Inc., 2015, “ANSYS Fluent 16.2 User's Guide”.

[2] Rolls-Royce plc Ultrafan ${ }^{\circledR}$ engine with epicyclic gearbox, accessed November 2016, https://www.flickr. com/photos/rolls-royceplc/14151477988/in/album$72157644584413758 /$.

[3] Townsend, D. P., 1991, “Dudley's Gear Handbook”, 2nd edition, McGraw-Hill.

[4] Berthold, M. et al., 2017, "Toward Investigation of External Oil Flow from a Journal Bearing in an Epicyclic Gearbox", ASME J. Eng. Gas Turbines Power, 140(6), pp. 062501-1-062501-9.

[5] Youngs, D. L., 1982, "Time-Dependent Multi-Material Flow with Large Fluid Distortion", Numerical Methods for Fluid Dynamics, Academic Press.

[6] ANSYS Inc., 2015, "ANSYS Fluent 16.2 Theory Guide".

[7] Ubbink, O., 1997, "Numerical prediction of two fluid systems with sharp interfaces", $\mathrm{PhD}$ thesis, Imperial College of Science.

[8] ANSYS Inc., 2014, "Multiphase Flow Modeling with Free Surfaces Flow", presented at the 2014 Korea Convergence Conference by Jinwon Seo, accessed January 2018, http:// www.ansys.com/resource-library/presentation/multiphaseflow-modeling-with-free-surfaces-flow/.

[9] Fraser, R. P. et al., 1963, "The Filming of Liquids by Spinning Cups", Chemical Engineering Science, Vol. 18, pp. 323-337.

[10] Hinze, J. O.; Milborn, H., 1950, “Atomization of Liquids by Means of a Rotating Cup", ASME Journal of Applied Mechanics, Vol. 17, pp. 145-153.

[11] Kamiya, T.; Kayano, A., 1972, "Film-type Disintegration by Rotating Disk", Journal of Chemical Engineering of Japan, Vol. 5, pp. 174-182.
[12] Liu, J., 2012, "Experimental Investigation of Liquid Disintegration by Rotary Cups", Chemical Engineering Science, Vol. 73, pp. 44-50.

[13] Glahn, A. et al., 2002, "Droplet Generation by Disintegration of Oil Films at the Rim of a Rotating Disk", ASME J. Eng. Gas Turbines Power, Vol. 124, pp. 117-124.

[14] Friedrich, M. A. et al., 2008, “A Separation Criterion with Experimental Validation for Shear-Driven Films in Separated Flows", Journal of Fluids Engineering, Vol. 130.

[15] Arai, T.; Hashimoto, H., 1985, "Disintegration of a Thin Liquid Sheet in a Concurrent Gas Stream” Proceedings of the Third International Conference on Liquid Atomization and Spray Systems.

[16] Khonsari, M. M.; Booser, E. R., 2008, “Applied Tribology - Bearing Design and Lubrication”, 2nd Edition, John Wiley \& Sons Ltd.

[17] Szeri, A., Z., 1980, "Tribology - Friction, Lubrication, and Wear", McGraw-Hill.

[18] Lang, O. R.; Steinhilper, W., 1978, “Gleitlager”, SpringerVerlag.

[19] COMSOL Inc., 2016, “COMSOL Multiphysics 5.3 User’s Guide".

\section{ANNEX A}

Table 4: CFD model key boundary conditions and parameter settings

\begin{tabular}{|l|l|}
\hline \multicolumn{1}{|c|}{ Parameter } & \multicolumn{1}{c|}{ Value/setting } \\
\hline Numerical solver & ANSYS Fluent \\
\hline Multi-phase model & VoF \\
\hline Energy model & Isothermal \\
\hline Turbulence model & $k$ - $\omega$ SST \\
\hline Flow discretization scheme & Second order \\
\hline $\begin{array}{l}\text { Volume fraction } \\
\text { discretization scheme }\end{array}$ & Geo-reconstruct, compressive \\
\hline Time-step $\Delta t$ & $2 \times 10^{-7} \mathrm{~s}, 5 \times 10^{-7} \mathrm{~s}, 1 \times 10^{-6} \mathrm{~s}$, \\
\hline Pressure-velocity coupling & $5 \times 10^{-6} \mathrm{~s}, 1 \times 10^{-5} \mathrm{~s}$ \\
\hline Air density $\left(30^{\circ} \mathrm{C}\right)$ & Pressure-based coupled solver \\
\hline Air viscosity $\left(30^{\circ} \mathrm{C}\right)$ & $1.165 \mathrm{~kg} / \mathrm{m}^{3}$ \\
\hline Oil density $\left(30^{\circ} \mathrm{C}\right)$ & $1.87 \times 10^{-5} \mathrm{~kg} /(\mathrm{m} \mathrm{s})$ \\
\hline Oil viscosity $\left(30^{\circ} \mathrm{C}\right)$ & $985.3 \mathrm{~kg} / \mathrm{m}^{3}$ \\
\hline Surface tension model & $0.047 \mathrm{~kg} /(\mathrm{m} \mathrm{s})$ \\
\hline Surface tension $\left(30{ }^{\circ} \mathrm{C}\right)$ & Enabled \\
\hline Rotational speed of gear & $0.03158 \mathrm{~N} / \mathrm{m}$ \\
\hline $\begin{array}{l}\text { Rotational speed of carrier } \\
\text { and journal }\end{array}$ & $\Omega=\Omega_{\mathrm{MTO}}$ \\
\hline Inlet type & rad $/ \mathrm{s}$ \\
\hline Air inlet mass flow rate & $0 \mathrm{~kg} / \mathrm{s}$ \\
\hline Oil inlet mass flow rate & $\dot{m}$ oil $=\dot{m}_{\text {oil,MTo }}$ \\
\hline Outlet type & Pressure outlet \\
\hline
\end{tabular}

